\title{
«La medida de su existencia». La abolición de las comunidades indígenas y el juicio de amparo en el contexto desamortizador. (Centro de México, 1856-1910)
}

\author{
por \\ Daniela Marino \\ INAH / Escuela Nacional de Antropología e Historia, México \\ cdanim@yahoo.com
}

Este trabajo indaga sobre el proceso administrativo y judicial de reparto de la propiedad comunal de la población indígena. Examina las consecuencias de algunas medidas tomadas por estados del centro de México para subsanar escollos legales, así como la actuación de los tribunales. Mediante el análisis de expedientes de juicios de amparo presentados por individuos, grupos y pueblos busca determinar cuáles fueron los roles jugados por la legislación, la jurisprudencia y las prácticas jurídicas de los actores en la transformación de la cultura de la propiedad, y cómo se imbricó este proceso con la construcción del Estado y la ciudadanía.

Palabras Clave: juicio de amparo; comunidad indigena; desamortización; centro de México.

La de 1857 fue la primera constitución de México en promulgar dos elementos esenciales del liberalismo: primero, la propiedad como derecho individual, al incorporar, en su artículo 27, disposiciones de la ley de desamortización de 1856 que abolía la propiedad corporativa amortizada y la personalidad jurídica de los actores colectivos en cuestión de bienes inmuebles; $\mathrm{y}$, segundo, una declaración de garantías individuales y un recurso para hacerlas cumplir: el juicio de amparo. Este fue reglamentado por sucesivas leyes en1861, 1869 y 1882, coincidiendo la última con importante jurisprudencia de la Suprema Corte referida a la imposibilidad de que siguiera existiendo propiedad comunal y de que las comunidades se apersonaran en juicio para dirimir litigios sobre tierras. 
Este trabajo indagará sobre aspectos del proceso administrativo y judicial de reparto de la propiedad comunal de la población indígena. En particular examinará las consecuencias de algunas medidas tomadas por gobernadores de estados del centro de México (particularmente Puebla, México e Hidalgo) para subsanar los escollos de la desamortización, así como la actuación de los tribunales, puesto que la misma no fue unánime en cada ocasión ni homogénea a lo largo del periodo. Para ello, se analizarán expedientes de juicios de amparo que sobre tierras presentaron individuos, grupos y pueblos del centro de México durante el periodo señalado. En primer lugar, a través de los mismos se pretende determinar quiénes estaban utilizando el recurso de amparo en cuestiones agrarias, de qué manera y con cuáles fines. Interesa ubicar en ese universo la representación de la comunidad extinguida: si siguió siendo posible como tal o quiénes - uno o varios vecinos, las autoridades tradicionales, el ayuntamientose abrogaron dicha representación, qué argumentos jurídicos utilizaron para defender y/o reclamar propiedad comunal y cómo sentenciaron estos juicios los tribunales locales y federales. En segundo lugar, se explorará cuáles fueron los roles jugados por la legislación, la jurisprudencia y las prácticas jurídicas de los actores afectados en transformar la cultura de la propiedad. Finalmente, se busca entender cómo se imbricó esa transformación con la propia construcción del Estado y la ciudadanía y, en ese sentido, de qué maneras el amparo (en este caso en materia agraria) fue también un recurso para, desde el centro, controlar e instruir a las autoridades y actores locales en diversos asuntos de constitucionalidad, jurisdicción, competencia, respeto a los derechos individuales, etc.

La materia agraria no es el único tema del amparo, pero dado su impacto sobre un sector muy importante de la población mexicana, se considera un ámbito idóneo para dar cuenta de los procesos en torno al derecho vigente, las ideas y prácticas jurídicas y administrativas, y aún los actores y procedimientos involucrados en los profundos cambios sociales propuestos por los gobiernos de la segunda mitad del siglo XIX. Además, la desamortización ha sido generalmente tratada desde la historia económica y legislativa $\mathrm{y}$, más recientemente, desde la historia regional y los estudios subalternos ${ }^{1}$. El pre-

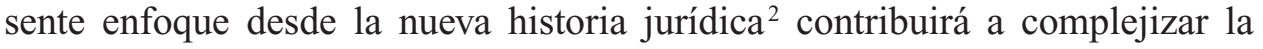

\footnotetext{
${ }_{1}^{1}$ Un análisis de la historiografía mexicanista de la segunda mitad del siglo XX en Marino, 2001. Un balance más reciente en Escobar, 2012.

${ }^{2}$ Entiendo por «nueva historia jurídica» un movimiento crítico iniciado dentro de la historia del derecho escrita por juristas de la Europa meridional, desde hace ya cuatro décadas, bajo la influencia de la renovación historiográfica post Annales, así como desde las ciencias sociales, particularmente la antropología y la sociología, y a las que Jesús Vallejo añade el compromiso político de estos juristas. Esta crítica a la vieja historia del derecho (positivista, glosadora del texto de la ley, interesada por la genealogía de las instituciones) se dirige tanto
} 
visión de dicho proceso al insertarlo en el programa de descorporativización de la sociedad ${ }^{3}$ y en la consolidación del Estado decimonónico. En un primer apartado se contextualizará brevemente estos procesos para, a continuación, desarrollar el problema específico planteado.

\section{EL INDIVIDUALISMO ECONÓMICO}

Desde su participación en el proceso gaditano y a lo largo del siglo XIX, las élites mexicanas acompañaron la construcción del Estado con una adecuación de los marcos legales. De aquellos heredados de su pertenencia al Imperio Español se cuestionaron los que no correspondían a los modelos republicanos que ilustraban los debates sobre el nuevo sistema de gobierno que había que definir tras la renuncia a la monarquía. Generalmente lenta y no exenta de conflictos, dicha adecuación tuvo, sin embargo, algunos momentos de radical transformación. En lo que respecta a los ideales liberales de secularización y descorporativización de la sociedad, el periodo de mayores planteamientos legislativos corresponde al conocido como la Reforma, iniciado con la presidencia de Juan Álvarez emanada del Plan de Ayutla que derrocó a Antonio López de Santa Anna en $1855^{4}$.

a la forma en que se hace cuanto a la función reproductora de la ideología estatalista que esa manera de hacer historia comporta: tanto por su proceder ahistórico, al imponer categorías del derecho y la política contemporáneos a sociedades pre-estatalistas o en proceso de construcción estatal, cuanto porque desterraba no sólo a la ilegalidad sino incluso al atavismo y la sinrazón cualquier forma jurídica no emanada del propio Estado. En este último sentido, quienes escriben la nueva historia jurídica se han acercado a los nuevos historiadores políticos. Ver Vallejo, 1995. Hespanha, 1996. Schaub, 1995. Garriga, 2004.

${ }^{3}$ Este tema ha sido abordado en Lira, 2003 y Lempérière, 2003.

${ }^{4}$ La presidencia interina de Álvarez sólo duró dos meses, nombrando él mismo como su sucesor provisorio a Ignacio Comonfort, quien asumió el cargo en diciembre de 1855, formó nuevo gabinete y renunció a fines de 1857, luego de promulgar la nueva constitución, jurar como presidente constitucional y permitir el golpe de Estado del militar conservador Félix Zuloaga contra su gobierno y la constitución liberal. A raíz de la renuncia de Comonfort y luego de huir de la ciudad de México, el presidente del Tribunal de Justicia (el autorizado en la nueva constitución para asumir la titularidad del poder ejecutivo en ausencia temporal o definitiva del presidente), Benito Juárez, se proclamó presidente y encabezó la lucha contra la facción conservadora en la que sería llamada Guerra de Reforma o Guerra de los Tres Años, hasta su regreso triunfal a la ciudad de México en diciembre de 1860. Debió abandonarla nuevamente en 1862, tras la invasión francesa apoyada por los conservadores y hasta el fusilamiento del emperador Maximiliano de Habsburgo, quien reinó sobre la mitad del territorio nacional entre 1864 y 1867. Estos diez años de guerra obstaculizaron la puesta en práctica de la desamortización civil en la mayor parte del territorio nacional. Un panorama general de este periodo es Lira y Staples, 2010: 448-478. 
Si bien la mayor oposición que despertó en los años siguientes obedeció a los embates contra los privilegios y poderío económico hasta entonces detentados por la Iglesia católica, la descorporativización también implicaba la abolición de las todavía existentes comunidades indígenas, aunque éstas, a diferencia de las eclesiásticas, no contaron con ardientes defensores en la prensa ni la tribuna ${ }^{5}$. La Ley de desamortización de fincas rústicas y urbanas de corporaciones civiles y eclesiásticas, redactada por el Secretario de Hacienda Miguel Lerdo de Tejada y promulgada el 25 de junio de $1856^{6}$ fue el puntapié inicial de dicha política ${ }^{7}$. El artículo $1^{\circ}$ establecía la adjudicación en propiedad de «todas las fincas rústicas y urbanas que hoy tienen o administran como propietarios las corporaciones civiles o eclesiásticas» a los actuales arrendatarios, quienes pagarían a las corporaciones lo mismo que pagaban de renta, calculado el precio como rédito al $6 \%$ anual. Luego de tres meses, las fincas no desamortizadas podían ser denunciadas por particulares y se pondrían en subasta. El artículo $8^{\circ}$ exceptuaba de la desamortización solamente los edificios destinados «inmediata y directamente» al objeto de la institución, así como los ejidos de los pueblos.

El territorio nacional se organizaba administrativamente en estados y estos a su vez en municipios encabezados por ayuntamientos. Ininterrumpidamente desde 1820, ya no existían pueblos de indios ni sus cabildos, al menos desde el punto de vista jurídico. Sin embargo, la realidad social y étnica que habían representado en los últimos tres siglos no era tan fácil de desaparecer. La ley y su reglamento tenían importantes lagunas respecto a las dificultades de instrumentación de la individualización de la propiedad: tanto por el contexto material y cultural de la época (regiones con altísima proporción de población indígena en comunidad; precarios medios de comunicación y transporte, estadística pública y cartografía; diversidad regional de unidades de medida, falta de catastros, múltiples formas y títulos de propiedad, escasez de agrónomos e ingenieros), como por la penuria económica y el bajo nivel educativo de las autoridades locales encargadas de llevarla a la práctica; a lo que debían

${ }^{5}$ Los «pueblos de indios» creados por la Corona tras la conquista habían quedado abolidos con la Constitución de Cádiz, lo mismo que todas las instituciones de carácter estamental inherentes al régimen de tutela de la Corona (tributo, cabildo, Tribunal de Indios, Hospital de Indios, etc.), así como la propia categoría jurídica de «indio». No obstante, núcleos de población indígena con posesión de tierras y bienes comunales persistían como localidades, en la práctica semi-autónomas, dentro de los municipios decimonónicos. Ver Marino, 2010: passim.

${ }^{6}$ En Gutiérrez, 1869, tomo II: 9-56.

7 Análisis de las políticas agrarias del periodo aquí tratado en Marino y Zuleta, 2010: passim. Gómez Galvarriato y Kouri, 2010: 96-117. Por supuesto, hubo antecedentes en la primera mitad del siglo y algunos autores remontan dicha política hasta las reformas borbónicas. 
añadírseles diferencias culturales y lingüísticas entre éstas y los grupos sujetos a la desamortización. Ante ello, se dictaron medidas facilitadoras (como la extensión de plazos y la exención del pago de alcabala a propiedades valuadas en menos de $\$ 200$ ) y numerosas circulares que respondían a las dudas planteadas por las autoridades de muchas de las entidades federativas. No obstante las dificultades, como aclarara el propio Lerdo al gobernador de Michoacán,

Incuestionable es que no debe tolerarse la subsistencia de las comunidades de indígenas, procurándose por el contrario la repartición de los bienes de que han sido propietarias, $y$ este es cabalmente uno de los principales preceptos de la ley [...] Previniéndose en la ley de 25 de Junio que los arrendatarios que soliciten la adjudicación en tiempo hábil, tienen derecho a que se les otorgue [...] aun cuando los terrenos arrendados pertenezcan a comunidades de indígenas. En cuanto a los no arrendados y a los en que el arrendatario no haga uso de su derecho, S.E. ha acordado que se repartan entre los mismos indígenas [...] es de creerse que los terrenos arrendados, han de ser muy pocos en comparación de los que queden para repartir, de manera que los indígenas contarán siempre con los necesarios, sin perjuicio de recibir el importe de los réditos de los que se adjudiquen a los inquilinos. Por tales consideraciones no debe temerse que se introduzca el descontento en esa clase [...] cuando en vez de dañar a los indígenas, se les favorece convirtiéndolos en propietarios, no hay motivo alguno para desórdenes y asonadas ${ }^{8}$.

La ley Lerdo no solamente generó descontento, y revueltas, sino que su incorporación en el artículo 27 de la Constitución de 1857 aumentó, de un lado, el temor por parte de los pueblos y, de otro, las dudas y los abusos de los aplicadores de la desamortización: el primer párrafo del breve artículo constitucional establecía que la propiedad era «de las personas», limitando ese derecho sólo por causa de utilidad pública y mediante expropiación; el segundo reiteraba el artículo 25 de la ley Lerdo, que quitaba a todas las corporaciones, civiles y eclesiásticas, la «capacidad legal para adquirir en propiedad o administrar por sí bienes raíces, con la única excepción de los edificios destinados inmediata y directamente al servicio u objeto de la institución», olvidando citar expresamente a los ejidos entre las excepciones ${ }^{9}$.

${ }^{8}$ Resolución de Miguel Lerdo de Tejada al gobernador de Michoacán, 19 de diciembre de 1856, en Gutiérrez, 1869, tomo II: 757-758. El subrayado es mío.

9 Constitución política de la República Mexicana, promulgada el 11-03-1857, Tena Ramírez, 1957: 606-629, el art. 27 en p. 610. 


\section{EL INDIVIDUALISMO JURÍDICO}

La anulación de la personalidad jurídica de las corporaciones provocó un sinfín de complicaciones a la de por sí difícil desamortización civil, pues significaba que las comunidades no podían realizar ningún acto jurídico sobre su propiedad colectiva, ni siquiera presentarse a juicio en caso de demandas o abusos sobre ella ${ }^{10}$. Además tampoco los ayuntamientos podían hacerlo en su nombre. Sin embargo, la Constitución de 1857 incorporó otras innovaciones: una declaración de derechos del hombre (art. 1 al 29) y un recurso para garantizar su cumplimiento, el juicio de amparo (art. 101 y 102) ${ }^{11}$. Éste protegía exclusivamente derechos y garantías del individuo en cuanto persona humana, en virtud del principio de igualdad jurídica y sólo contra actos arbitrarios de las autoridades ${ }^{12}$. Fue reglamentado por primera vez en 1861, siendo dicha ley reformada sucesivamente en 1869, 1882 y por el Código de Procedimientos Civiles de 1897 con el mismo objetivo que la ley original, aunque afinando su instrumentación. La ley de 1861 había abierto la posibilidad de que el recurso de amparo cursara frente actos arbitrarios de autoridades civiles y judiciales, lo que dio pie a un cúmulo de presentaciones que lo tomaban como una cuarta instancia. Por esa razón se modificó la ley en 1869, aclarando que sólo se amparaban derechos individuales frente a abusos de la autoridad civil, estableciendo dicho recurso como extraordinario y a la Corte como el tribunal

${ }^{10}$ Así quedó establecido en la ejecutoria de la Suprema Corte de Justicia de 9 de enero de 1879, que resolvió, a su favor, el amparo presentado por la Sra. Servín de Capetillo contra actos del Juez letrado de Tlalnepantla que dio curso a la solicitud del pueblo de Cahuacan para realizar diligencia de apeo y deslinde de sus terrenos en presencia de los propietarios colindantes; en adelante Amparo Capetillo, en González Oropeza, 1993: 313-314.

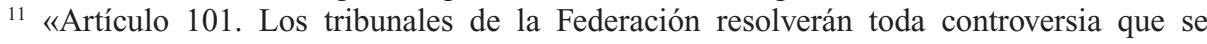
suscite:

I. Por leyes o actos de cualquier autoridad que violen las garantías individuales.

II. Por leyes o actos de la autoridad federal que vulneren o restrinjan la soberanía de los estados.

III. Por leyes o actos de las autoridades de éstos, que invadan la esfera de la autoridad federal.

Artículo 102. Todos los juicios de que habla el artículo anterior se seguirán, a petición de la parte agraviada, por medio de procedimientos y formas de orden jurídico, que determinará una ley. La sentencia será siempre tal, que solo se ocupe de individuos particulares, limitándose a protegerlos y ampararlos en el caso especial sobre que verse el proceso, sin hacer ninguna declaración general respecto de la ley o acto que la motivare», en Tena Ramírez, 1957: 623624 , comillas altas mías.

${ }_{12}$ Las garantías usualmente reclamadas en los juicios de amparo de esta época fueron: a la igualdad, la libertad, la propiedad y la seguridad jurídica. Lira, 1972: 99. Rhi Sausi, 2010: 138 y ss. Ver también, en lo referente a los grupos indígenas y la propiedad comunal, Marino, 2005a. 
de última instancia. Esta última ley también especificó los procedimientos de publicación de las sentencias firmes de amparo, dando inicio a la jurisprudencia mexicana. Estuvo reforzada por la ley de 1882, que reglamentó la suspensión del «acto reclamado» ${ }^{13}$ y estableció el tiempo -desde la comisión de aquél- válido para interponer el amparo; además, dio intervención en el juicio a la autoridad demandada y a la tercera parte perjudicada ${ }^{14}$.

Pese a ser un recurso de defensa del individuo, ciertas personas morales tenían personalidad jurídica y podían litigar en asuntos de propiedad. Entre ellas no solo estaban las sociedades mercantiles, sino también los ayuntamientos y las corporaciones eclesiásticas en lo relativo a los inmuebles destinados a sus fines específicos (cementerio, rastro, palacio municipal, los primeros; lugares de culto, hospicios, casas de la curia, las segundas). Sin embargo, los pueblos, barrios y comunidades (y municipios respecto de los propios y otros terrenos) carecían de ella. Eso creó serios problemas jurídicos a la hora en que los estados procedieron a la desamortización de los bienes comunales de los pueblos, en muchos casos sin títulos legales, o con títulos ambiguos en cuanto a delimitar exactamente los terrenos que referían y, por tanto, con derechos de propiedad disputados entre pueblos vecinos y entre pueblos y particulares.

Frente a esta situación, algunos estados decretaron medidas para dar cauce legal a la creciente conflictividad agraria, aunque la del estado de México (también vigente en Hidalgo) y la de Veracruz fueron declaradas anticonstitucionales por la Suprema Corte de Justicia. El Estado de México había dispuesto en 1868 que los pueblos y comunidades con propiedades contendidas por particulares u otros pueblos debían someter su caso al jefe político, para que fuera éste quien decidiera si el caso ameritaba un «permiso para litigar» y poder así dirimirlo en juicio en los tribunales locales (en clara contravención con la legislación federal). Los pueblos que querían litigar también debían someter a su consideración la persona elegida como su apoderado legal. Diez años después, se modificó dicha ley para otorgar ambas prerrogativas sólo al Ejecutivo estatal, aunque éste decidiría luego de recibir el expediente razonado

${ }^{13}$ Este concepto, propio del juicio de amparo, se incorporó en la Ley reglamentaria de 1869, en el título del Capítulo 1: «Introducción del juicio de amparo y suspensión del acto reclamado»y y en el texto de varios artículos de dicha ley. La Ley reglamentaria de 1882 mantuvo el uso de dicho concepto, que aparece desde el texto del artículo 4. Desde entonces es habitual su uso en la sustanciación de los juicios de amparo y refiere al acto específico de la autoridad que el quejoso considere violatorio de alguna de sus garantías individuales o ley que estime inconstitucional.

${ }^{14}$ Las leyes reglamentarias del amparo y el Código Federal de Procedimientos de 1897, en Dublán y Lozano, 2004. 
formado por el jefe político respectivo y con asesoramiento de su consejo de gobierno ${ }^{15}$. En 1878-1880 esta medida recibió tres reveses de jueces federales.

El 8 de marzo de 1879, el Juzgado de Distrito del Estado de México, a cargo del Lic. José Romero, amparó a ciento doce vecinos del pueblo de Santa María Atarasquillo contra actos del presidente municipal y el juez de primera instancia de Lerma en la desecación y posterior división de la ciénaga de Chignahuapan, que los «promoventes» ${ }^{16}$ consideraban de su propiedad y que el presidente municipal repartió entre vecinos de la ciudad de Lerma. El Juzgado reconvino al juez de $1^{\circ}$ instancia porque

[...] al no oir en justicia a los promoventes, fundado en el decreto núm. 104 de 17 de Octubre de 1878, ha vulnerado los arts. 17 y 126 de la Constitución; el primero no administrando pronta y cumplida justicia, y el segundo porque con violación de los preceptos de este artículo y el 27 citado, ha fundado su negativa en exigirles un requisito ${ }^{17}$ que daría a los promoventes personalidad legal como pueblo, personalidad de que carecen desde que se expidió la ley de 25 de Junio de 1856 y su concordante el art. 27 de la Constitución ${ }^{18}$.

De manera indirecta, otras ejecutorias habían desestimado la medida. En junio de 1878, en el ya citado Amparo Capetillo, el Juez de Distrito negó el amparo a la Sra. María de la Luz Servín y, en ese sentido, consideró correcta la actuación del juez de primera instancia de Tlalnepantla que había ordenado a los colindantes de Cahuacán (entre ellos, la promovente) estar presentes en la acción de apeo y deslinde, con lo cual reconocía personalidad jurídica a dicho pueblo. No obstante, en enero del año siguiente, al revisar el amparo del inferior, la Suprema Corte de Justicia de la Nación no estuvo de acuerdo con los criterios del juez letrado ni del juez de distrito y amparó a la Sra. Servín de Capetillo, considerando que el segundo párrafo del artículo 27 constitucional concedía a los propietarios de la República (entendidos como individuos) la garantía «que los libra de toda molestia, litigio o juicio que pudiera promoverles alguna corporación civil o eclesiástica a título de propietaria; porque una y otra

15 Artículo 15 de la "Ley orgánica para el gobierno y administración interior de los distritos políticos del estado" de 21 de abril de 1868 y "decreto no 104 de Juan N. Mirafuentes, gobernador constitucional del Estado libre y soberano de México" de 17 de octubre de 1878; ambos en Colección, 2001.

${ }^{16}$ Como «acto reclamado», «promovente» es también un concepto jurídico específico del juicio de amparo, y refiere a la o las personas que «promueven» o presentan el recurso, tal como aparece en la cita siguiente, tomada del expediente del Amparo Atarasquillo.

${ }_{17}$ Se refiere al permiso para litigar.

18 El Foro, 2da época, V/60, 1 de abril de 1879, Sección Jurisprudencia Federal: 237-238, en adelante: Amparo Atarasquillo. 
carecen de capacidad legal para adquirir en propiedad o administrar por sí bienes raíces». Esto implicaba que la diligencia de apeo y deslinde era una violación a dicha garantía, puesto «que la acción de deslinde no es más que un medio por el que se llega a la propiedad rústica y por eso la esencia del derecho dice que hace las veces de la vindicación de la cosa» ${ }^{19}$. Esta ejecutoria, emitida por la Corte presidida por el liberal Ignacio Ramírez, causó gran impacto en el medio jurídico de la época, y así como fue citada en sucesivas sentencias de tribunales locales y federales ${ }^{20}$, también fue motivo de debate en la prensa especializada ${ }^{21}$. Finalmente, en 1882, Ignacio Vallarta, como ministro presidente de la Suprema Corte, redactó cinco dictámenes en sendos juicios de amparo que sentaron la jurisprudencia definitiva sobre la inexistencia legal de las comunidades de indios ${ }^{22}$. En uno de esos votos opinó sobre el Amparo Capetillo, argumentando que había sido hasta entonces mal interpretado, en el sentido de que privaba a los indígenas de derechos individuales sobre los bienes que anteriormente pertenecían a la comunidad ${ }^{23}$. En opinión de Vallarta, la circular del 19 de diciembre de 1856 -aclaratoria de la Ley Lerdo- había demostrado que las comunidades de indígenas, como corporaciones perpetuas, no eran capaces del derecho de propiedad y no podían seguir existiendo; pero la circular también exhortaba al reparto de los terrenos no arrendados entre sus ex-miembros. En sus palabras:

[...] la corporación no autorizada, más aún, prohibida por la ley, es incapaz de vida jurídica, no tiene derechos civiles, no puede exhibirse como persona viviente ante los tribunales [...] Si además de esto no se olvida que la capacidad artificial de la [..persona jurídica..], considerada civilmente, no tiene por objeto más que los bienes, $[\ldots]$ se verá $[. .$.$] que la corporación a quien se prohibe adquirir y administrar$ bienes raíces, queda por ese simple hecho muerta ante la ley ${ }^{24}$.

19 Amparo Capetillo, en González Oropeza, 1993: 314.

20 Por ejemplo, "Sentencia de 31 de enero de 1880 del juez de distrito del Estado de México, que niega el amparo a los vecinos de Metepec", en Cabrera Acevedo, 1990: 282-284.

${ }^{21}$ El abogado más notorio en defensa de esta postura fue Isidro Montiel y Duarte (juez, catedrático, promotor fiscal de la Suprema Corte, legislador, secretario de estado...), quien editorializó a favor del criterio sentado por la Corte en el Amparo Capetillo en El Foro los días 25 y 27 de marzo de 1879; reproducida, junto con una crítica de un abogado menos conocido, en Cabrera Acevedo, 1990: 269-272 y 276-277.

22 Ver Marino, 2005a.

${ }^{23}$ Amparo pedido por el apoderado de los indígenas de Chicontepec, contra el acto del gobierno de Veracruz que mandó vender parte de los terrenos de comunidad para pagar los gastos del repartimiento de los restantes (en adelante Amparo Chicontepec), en Vallarta, 1896, tomo IV: 26 y nota 2.

${ }^{24}$ Amparo pedido contra el apeo y deslinde de terrenos solicitado por el común de un pueblo (Santiago Mitlatongo) que alega tener derechos de dominio y posesión en ellos (en adelante Amparo Mitlatongo), en ibidem: 56 y 58-59. El subrayado es mío. 
Y frente a la demanda de que permitirles participar en los juicios resolvería los derechos de propiedad en litigio, para poder dar certeza jurídica a la desamortización, en el amparo emprendido por el pueblo de Santiago Mitlatongo fue muy tajante en señalar:

Absurdo incompatible con el principio político y económico proclamado en la ley, habría sido la supervivencia de la comunidad amortizadora, so pretexto de sostener los pleitos que respecto de la propiedad estancada se suscitaran [...] porque sin esfuerzo se comprende que ella bien cuidaría de eternizar los pleitos, que habían de ser la medida de su existencia ${ }^{25}$.

No obstante, en este mismo amparo, aclaraba el modo correcto de definir judicialmente el mejor derecho a la propiedad: «toca a los miembros de las extinguidas comunidades ejercer los derechos que antes competían a ellas; éstos son por tanto quienes, representados legalmente, deben apersonarse en los juicios» ${ }^{26}$, al tiempo que reconocía las enormes dificultades que esta solución acarreaba a los indígenas.

Asimismo, en el Amparo Chicontepec, en el que se dirimía además la medida tomada por el estado de Veracruz de otorgar personalidad jurídica a los ayuntamientos para que resolvieran la desamortización y conflictos de propiedad comunal de sus pueblos, Vallarta adelantaba la inconstitucionalidad de estas iniciativas estatales, a la par que les reconocía atribuciones para implementar el reparto entre los indígenas.

Si bien los Estados carecen de facultades para dar a corporación alguna de carácter perpetuo capacidad legal para adquirir en propiedad o administrar por sí bienes raíces; para reconocer a las comunidades de indígenas como persona jurídica capaz del derecho de propiedad [...], sí pueden dictar las medidas que juzguen más apropiadas para que él se respete y se cumpla; para que la desamortización que ordena quede consumada; para que los terrenos de los indígenas se repartan y disfruten por sus dueños, y cesen de ser el objeto de la codicia de avaros propietarios, el germen fecundo de pleitos que agentes intrusos promueven, el motivo o siquiera el pretexto de la perturbación de la paz pública en muchos pueblos ${ }^{27}$.

Estos problemas para desamortizar la propiedad comunal eran obstáculos cotidianos para los presidentes municipales y jefes políticos de las regiones con núcleos de población indígena. Para resolverlos presionaban a los gobiernos estatales por medidas ejecutivas. Como lo expresó, de forma un tanto deses-

\footnotetext{
25 Ibidem: 53.

${ }^{26}$ Ibidem: 49.

27 Ibidem: 20-21.
} 
perada, un presidente municipal, mestizo e interesado en la desamortización de un monte comunal, en una carta dirigida al gobierno del estado:

[...] suplico a U. se sirva dirigirse a los CC. Jefes Políticos de las Cabeceras de Tlalnepantla y Lerma para que como árbitros en este asunto procuren una transacción amistosa entre los contendientes de sus respectivas demarcaciones para cortar de raíz la cuestión existente entre dos pueblos hermanos y circunvecinos que si se deja arraigar será en lo futuro de funestas consecuencias, pues nuestros hijos recibirán como legado esta cuestión y por consiguiente será interminable; quedando sin poderse fraccionar los terrenos de que se $\operatorname{trata}^{28}$.

Ello explica que otro de los dictámenes de Vallarta tuviera por materia específica el «permiso para litigar» legislado por el estado de México y que también se aplicaba, como en este caso, en el estado de Hidalgo (separado del estado de México un año después de expedida dicha ley). La Suprema Corte determinó su inconstitucionalidad, con base en dos argumentos: Si se trataba de comunidades, ni con la licencia del jefe político podían estas litigar, pues estarían infringiendo la segunda parte del artículo 27 constitucional y, si, por el contrario, se trataba de actores individuales, el posible veto de una autoridad significaría una restricción al derecho de propiedad, violando la primera parte de dicho artículo. Por tanto, el decreto «nunca puede considerarse [...] como obligatorio para el caso en que muchos comuneros en su carácter individual quieran litigar, aunque ellos sean indios, aunque por su número constituyan lo que antes se llamó comunidad» ${ }^{29}$.

En cambio, el estado de Puebla pudo encontrar una mejor solución que no confrontaba con la constitución federal ni la Ley Lerdo. El decreto 122, promulgado en mayo de 1869, disponía que «los litigios pendientes entre pueblos del estado, o los que en lo sucesivo se promuevan, serán terminados por medio de árbitros amigables componedores, uno por cada parte, que nombrarán los representantes de los ayuntamientos o pueblos interesados». El artículo 2 expresaba que «en ningún caso serán nombrados para estos cargos los llamados "tinterillos", ni aquellos que careciendo de medios para subsistir tienen adoptada la costumbre de andar en los pueblos promoviendo pleitos»; para ello, recaía en el Jefe Político la calificación de los árbitros (art. $3^{\circ}$ ) e incluso

${ }^{28}$ Carta del presidente municipal de Huixquilucan al Secretario General de Gobierno del Estado de México, 12-07-1890, Archivo Histórico Municipal de Huixquilucan, Mexico (en adelante AHMH), Tierras, vol. 4, leg. 13.

${ }^{29}$ Amparo pedido contra la ejecutoria del Tribunal del distrito que negó a unos pueblos de indígenas la personalidad para litigar, en adelante Amparo Hidalgo, en Vallarta, 1896, tomo IV: 570-571. El subrayado es mío. 
el nombramiento cuando los pueblos no quisieren nombrar árbitro (art. $4^{\circ}$ ). $\mathrm{Si}$ los pueblos litigantes pertenecían a distritos distintos, esa función recaía en el Gobernador (art. $5^{\circ}$ ); asimismo, cuando un pueblo litigara con un particular, «el ejecutivo hará todo lo posible para que este se preste a que el litigio se decida...» igualmente por árbitros. Este último artículo salvó a la ley de ser declarada anticonstitucional, puesto que no obligaba a los individuos, sino a los pueblos, incluso cuando se resistieran a nombrar árbitro, como en el art. $4^{\circ}$. El término del conflicto se aseguraba además en el art. $8^{\circ}$, que estipulaba que nombrados los árbitros «se procederá a otorgar la escritura de compromiso respectiva, en la que se expresará que del laudo de los arbitradores o del tercero en su caso, no se admitirá a las partes otro recurso que el de responsabilidad». Finalmente, se establecía como objetivo resolver todas las cuestiones litigiosas de terrenos existentes, fijar los linderos y levantar los planos en un plazo de seis meses ${ }^{30}$. Este periodo, para un estado con algunas regiones de amplia población indígena, resultó demasiado optimista, y el mismo procedimiento de arbitraje fue objetado en algunos recursos de amparo.

Como podemos ver, la disposición poblana era similar a la mexiquense, con dos diferencias que resultaron fundamentales: 1) Puebla designaba árbitros, que podían no ser letrados, específicamente para resolver estos litigios por vía de «amigable composición», es decir, sin procedimiento judicial; mientras que el estado de México los encauzaba hacia el sistema estatal oficial de administración de justicia; 2) los jueces mexiquenses podían entonces citar a comparecer en juicio a particulares afectados o demandados, mientras que en Puebla los particulares no estaban obligados a participar en el arbitraje, si bien se procuraba su colaboración para dirimir los conflictos, muchas veces añejos, por «amigable composición». En consecuencia, al ser sólo una composición arbitral, el procedimiento poblano no incurrió en inconstitucionalidad; mientras que el del estado de México sí por ser judicial. No obstante, en ambos estados, muchos actores que obtenían una sentencia no favorable, decidieron continuar en los tribunales federales por medio del recurso de amparo.

Uno de los casos notorios a este respecto fue el amparo interpuesto por el licenciado José de Jesús López, representante legal de Doña María Josefa Apesechea, dueña de la hacienda Calipan, contra el jefe político y el juez de primera instancia del distrito de Tehuacán. Argumentaba que el decreto 122 era inconstitucional porque sujetaba los litigios de los pueblos al arbitraje obli-

${ }^{30}$ Periódico Oficial del Estado de Puebla, 3-6-1869, Archivo Histórico del Poder Judicial de Puebla (en adelante AHPJP), amparo 11/1872, $\mathrm{n}^{\circ}$ consecutivo 1570. También Mallon, 2003: 272-273, refiere diversas presentaciones de pueblos de la sierra norte de Puebla para hacer efectivo el decreto, al menos en 1869 y 1870. 
gatorio, creando leyes privativas y juzgados especiales ${ }^{31}$. En este caso, el juez de primera instancia había fungido previamente como árbitro para solucionar el añejo litigio por tierras entre la hacienda y el vecino pueblo de Ajalpan, duplicidad también considerada ilegal por la parte actora, pese a que, según la parte demandada, había sido nombrado de común acuerdo entre el hijo de la hacendada, Sr. Julián Cacho, y el pueblo, y con el consentimiento del jefe político. Tal vez su culpa había sido la de resolver el pleito en perjuicio de la hacienda, según los promotores del amparo.

El abogado patrocinador presentaba al hacendado Cacho como una persona ingenua, que había aceptado el arbitraje de buena fe y sin entender que el pueblo, en connivencia con el juez y el jefe político (antiguo apoderado de Ajalpan, según López), le estaban tendiendo una trampa, y argüía la inconstitucionalidad del decreto que sujetaba los litigios de los pueblos al arbitraje obligatorio, pues creaba leyes privativas y juzgados especiales. Además, señalaba los vicios observados en el arbitraje: falta de peritos y tercer árbitro, el juez de primera instancia no podía ser al mismo tiempo árbitro, y que el señor Cacho no tenía poder para representar a su madre pues él era su único representante legal. En contrapartida, el jefe político señaló en su informe que ambas partes se habían presentado libremente en su oficina para solicitar el arbitraje, y puesto que el decreto 122 no podía obligar a particulares a sujetarse al mismo no se había violado ninguna garantía individual. Añadió que si hubo malicia fue más bien de parte de Cacho, para que «Ajalpan quedara sujeto a la ley y sin recurso ulterior». También el juez Tello denunció ante el juez de distrito la mala fe de Cacho y López al presentar «la candidez, inocencia y poca instrucción» del primero, difícil de creer en alguien «versado en las intrigas parlamentarias como antiguo diputado al Congreso de la Unión» y aconsejado por «su digno maestro y director el Lic. López, una de las lumbreras del foro poblano».

El promotor fiscal pidió se declarara improcedente el amparo por carecer de fundamento legal, aprobando la constitucionalidad del decreto 122 puesto que los árbitros debían juzgar conforme a las leyes. Con el mismo criterio, tanto el juez de distrito como la Corte dictaron el sobreseimiento por unanimidad. Esta resolución mostraba el uso del recurso de amparo como un medio para evitar la aplicación de legislación estatal que no favorecía al actor, siendo sólo uno de los ejemplos donde el objetivo declarado de imponer un sistema moderno de propiedad individual no necesariamente jugaba a favor de los hacendados para desposeer a los pueblos indígenas, aún si el propio hacendado tenía notables influencias políticas, como hace suponer la condición de Cacho como ex diputado federal y su capacidad de contratar un abogado

\footnotetext{
${ }^{31}$ AHPJP, amparo 11/1872, $\mathrm{n}^{\circ}$ consecutivo 1570.
} 
de prestigio. Por supuesto, también existen ejemplos contrarios (v.g. el Amparo Capetillo). Por ello, lo que se pretende resaltar en este artículo es la complejidad de las luchas políticas y los mecanismos facciosos y clientelares locales, a la par que observar el derecho y la administración de justicia como instrumentos de la construcción de un sistema de propiedad liberal y de un aparato estatal. Así, en el caso de Puebla, el procedimiento de los «árbitros componedores» significaba la apelación a tradiciones jurídicas antiguas (como la conciliación lega, establecida como escaño inferior del sistema judicial en el ámbito municipal) ${ }^{32}$ para resolver, por vía pre-judicial, conflictos agrarios de larga data y gran número, que saturarían fácilmente la capacidad de administración de justicia de los sistemas judiciales federal y estatales. Por el contrario, el estado de Veracruz sólo buscó subsanar la falta de personalidad jurídica del actor comunal, aunque otorgándosela al ayuntamiento que entonces también carecía de personalidad en asuntos agrarios. Por su parte, el Estado de México confió en su poder judicial como ámbito cerrado donde resolver dichos litigios, aunque estableciendo un filtro previo por el cual la autoridad administrativa decidía a quiénes permitir litigar y a quiénes no. Esta solución estatal que se quiso soberana, fue desbaratada por la Suprema Corte cuando decidió jurisprudencialmente que a ella tocaba la última palabra respecto de constitucionalidad de los actos judiciales en todo el territorio nacional.

La jurisprudencia establecida en el año de 1882 persistió hasta finales del periodo de estudio, con la salvedad de que la ley de terrenos baldíos de 1894 permitió, aunque de manera temporal, la solución veracruzana de otorgar personalidad jurídica a los ayuntamientos sólo para resolver la desamortización de las tierras comunales. Esta aceptación, por parte del gobierno federal, de la necesidad de resolver los derechos de propiedad contenciosos para poder avanzar en la desamortización, siguió motivando la participación judicial de los pueblos, incluso por vía del amparo. De esta manera, las comunidades sólo estaban extinguidas en la ley, pero no en la sociedad mexicana, como reconocería otro presidente de la Suprema Corte de Justicia en 1902:

[...] el caso es que una vez expedidas las leyes de reforma, no puede ponerse en duda que las comunidades de indígenas no tienen ya una existencia legal y que no sólo no aparecen autorizadas o permitidas por la ley, requisito indispensable para considerarlas como entidades jurídicas [...], sino que su existencia pugna con el Derecho Público vigente desde el año de $1856^{33}$.

\footnotetext{
${ }^{32}$ Marino, 2005c.

${ }^{33}$ Moreno Cora, 1902, libro 1, cap. IV: "De la procedencia del amparo con relación a cada una de las personas morales que reconoce la ley".
} 
Precisamente la Suprema Corte de Justicia de la Nación presidida por Moreno Cora había resuelto favorablemente, el 25 de mayo de 1900, un recurso de amparo interpuesto por el síndico de la municipalidad mexiquense de Huixquilucan en representación de los pueblos de San Francisco y Santa Cruz Ayotuxco ${ }^{34}$. El objeto del juicio fue un terreno de propiedad comunal disputado desde hacía largo tiempo por dichos pueblos con el de San Lorenzo Huitzitzilapa, de la vecina municipalidad de Lerma. El expediente nos informa que «en las posesiones dadas respectivamente a esos pueblos en los años de 1709 y 1711, ambos manifestaron su conformidad en los linderos». Sin embargo, en 1809 ya existía testimonio de litigio entre ambos, mismo que reiniciaron en la segunda mitad del siglo XIX, so pretexto de cumplir con la ley de desamortización. Este último pleito judicial comenzó en 1887 y terminó trece años después con el amparo de la Suprema Corte, no obstante que la ejecutoria de amparo nunca resolvía el fondo del asunto, sólo ordenaba regresar el procedimiento administrativo o judicial al momento previo en que se violó alguna garantía constitucional. Sin embargo, no poseo información de dicha reposición y continuación del juicio hasta la sentencia definitiva que otorgara los derechos de propiedad a alguna de las partes. Pese a ello, es muy ilustrativo observar en este expediente las sucesivas etapas del camino judicial que seguían entonces los pueblos:

Primero, en noviembre de 1887, una parte de las tierras en disputa fue reclamada por San Lorenzo ante el Juzgado de Primera Instancia de Tlalnepantla. Dicho juicio se suspendió en la primera mitad de 1888 , hasta que el tribunal pronunció una sentencia definitiva el 10 de junio de 1895 condenando al pueblo de San Francisco Ayotuxco a devolver al pueblo de San Lorenzo Huitzitzilapa el terreno llamado «Damboxu». Segundo, se interpuso recurso de apelación, que la Segunda Sala del Tribunal Superior de Justicia del Estado de México falló el 26 de agosto de 1897, confirmando la sentencia de primera instancia en todas sus partes. Tercero, el síndico de Huixquilucan presentó un recurso de nulidad contra esa sentencia ante el mismo tribunal, alegando violaciones en cuanto al fondo del negocio y en cuanto a la forma del procedimiento. Este, en Tribunal Pleno, dictó sentencia el 6 de febrero de 1899, declarando improcedente la admisión del recurso de nulidad y confirmando el fallo de la Segunda Sala. También condenaba a los pueblos de Ayotuxco

${ }^{34}$ Solicitud de amparo de Urbano Gutiérrez y socios contra el fallo dictado por el Tribunal Superior de Justicia del Estado de México, Mayo 25 de 1900 (en adelante Amparo Gutiérrez), en Semanario Judicial de la Federación, $4^{\circ}$ época, tomo 5: 828-847. 
a la pérdida del depósito de $\$ 800$. Cuarto, Urbano Gutiérrez, como síndico del Ayuntamiento de Huixquilucan, y cuatrocientos treinta y dos individuos más presentaron amparo ante el Juzgado de Distrito del Estado de México. El 12 de diciembre de 1899 el juez de distrito lo negó, imponiéndoles una multa de $\$ 10$ a cada uno de los promoventes. Y, por último, el 22 de mayo de 1900 la Suprema Corte de Justicia de la Nación revisó el amparo, revocó la sentencia dictada por el Juez de Distrito del Estado de México y devolvió el expediente a la instancia anterior.

En este recuento en cinco fases se observa que un litigio en todas sus instancias podía durar largo tiempo y suponer una derrama económica considerable. Pero con ello se obtenía que a lo largo de esos trece años se mantuviera la posesión del terreno en cuestión, base de la subsistencia de la comunidad. La diferente interpretación legal, evidente en las sentencias emitidas, ilustraba las contradicciones entre los diferentes niveles y ámbitos del sistema judicial y la existencia de resquicios jurídicos que justificaban la persistencia de los pueblos en el camino judicial, más aún si se añaden las alternativas propuestas por los estados, algunas en franca contradicción con la constitución y las leyes federales. Así, se lee que el Juez de distrito negó el amparo «a los individuos que se dicen vecinos de los pueblos» de Ayotuxco por considerar que no era

...legal la representación judicial de los derechos comunales por los mismos y que antes de las leyes de Reforma tenían los pueblos al poseer bienes raíces de comunidad, y por no haber probado en este juicio la propiedad individual en las violaciones de que se quejan [...] Siendo la demanda de amparo que han promovido los vecinos [...] contrariando las leyes constitucionales que sólo protegen al individuo en sus derechos legales bien justificados... ${ }^{35}$

Mientras que al año siguiente la Suprema Corte de Justicia de la Nación sí les concedió el amparo, revocando tanto la sentencia del Juez de Distrito cuanto la del Tribunal Pleno de Justicia del Estado de México que desechara el recurso de nulidad, basándose en

el art. 69 de la ley de 26 de Marzo de 1894, que da personalidad a los Ayuntamientos para gestionar su repartición o fraccionamiento entre los individuos que a ello tengan derecho [...] siendo esa disposición legal de obligación general en toda la República... ${ }^{36}$

${ }^{35}$ Semanario Judicial de la Federación, $4^{\circ}$ época, tomo $5^{\circ}: 829$. El subrayado es mío.

36 Ibidem: 841. 
Asimismo, en que

... la misma Constitución y con las leyes de Reforma, las que al desamortizar los bienes raíces pertenecientes a comunidades de indígenas, no tuvieron por objeto desposeerlos de los terrenos que comprendían esas comunidades, ni permitir les fuesen arrebatados por quien no alegara mejor derecho, pues lo único que previenen esas leyes, elevadas al rango de constitucionales, es el reparto de dichos terrenos entre sus poseedores o legítimos dueños... ${ }^{37}$

Es decir que, a diferencia de lo sentenciado en 1882 en el Amparo Hidalgo, en esta ocasión y en virtud del cambio en la legislación, la Suprema Corte pudo permitir la presentación judicial de la comunidad representada por el síndico municipal. En relación a la cultura jurídica de los actores involucrados, puede concluirse que aún los más altos magistrados de la nación exhibían diferentes grados de dominio de la legislación vigente, distintas posiciones ideológicas $\mathrm{y}$ aún diversos criterios respecto de la propiedad indígena. $\mathrm{Y}$ esta diversidad se manifestaba incluso entre los magistrados que componían el pleno de la Suprema Corte de Justicia, de modo que no pocas sentencias de amparo eran aprobadas por mayoría y no por unanimidad. Por tanto, y en oposición a la calificación de «pleitistas» que tan frecuentemente recibían los indígenas, la contradicción de criterio entre los magistrados justificaba su persistencia en el camino judicial hasta obtener una sentencia favorable.

Además, las demandas presentadas por los pueblos apuntan a la utilización de las leyes anticorporativas en su propio beneficio. Al respecto, es interesante apreciar la estrategia jurídica del asesor de los vecinos de Ayotuxco, quienes justificaron su demanda de amparo en la violación del artículo 14 constitucional «por inexacta aplicación de las leyes que norman el procedimiento judicial», del artículo 16 «que previene que nadie puede ser molestado en su persona, familia, papeles y posesiones, sino en virtud de mandamiento escrito de autoridad competente que funde y motive la causa legal del procedimiento» y, sobre todo, en la violación de la garantía del artículo 27 constitucional, «tanto por la privación injustificada de su propiedad, cuanto por infringirse con la sentencia objeto del amparo la prohibición de la parte segunda del mismo artículo, al considerar a las corporaciones civiles con capacidad legal para adquirir por sí bienes raíces $\rangle^{38}$. Es decir, los pueblos apelaron al artículo anticorporativo de la constitución de 1857 para defender sus terrenos comunales de la pretensión de otro pueblo de «adquirirlos» por la vía judicial. Ese razonamiento fue utilizado por muchos abogados que patrocinaban juicios de

\footnotetext{
37 Ibidem: 843-844. El subrayado es mío.

38 Ibidem: 835. El subrayado es mío.
} 
comunidades indígenas ${ }^{39}$ y plenamente compartido por la Suprema Corte de Justicia de la Nación, si bien con el único fin de concretar el reparto de los mismos entre los individuos con derecho fundado a ello.

En definitiva, en un contexto de pluralidad de formas y títulos de propiedad (perfecta e imperfecta; individuales y corporativas; orales, pictográficos y escritos; por merced, por composición, por ocupación, por compra; a censo, con derechos de uso, derechos de paso, etc.) el proyecto liberal de encausarlo hacia el monismo jurídico de la propiedad perfecta (es decir, con derechos absolutos de posesión y uso en manos de un individuo propietario que ostenta el título legal a ellos), por medio de una legislación y unos procedimientos únicos, inconsultos y sumamente restrictivos, probó ser complicado de realizar. En ese proceso, los actores involucrados buscaron las maneras de adaptar su situación y sus expectativas al nuevo marco jurídico, sea para defender sus tierras de pretensiones ajenas, para mantenerlas en las mismas formas de uso, o bien para obtener más tierras a título individual o colectivo a costa de los derechos de sus vecinos. Esta última opción, incluyó las disputas entre dos o más pueblos, grupos sociales e incluso grupos étnicos dentro de un mismo municipio, para obtener los derechos de propiedad perfecta sobre viejos terrenos comunales, ejidos, montes y aún baldíos.

\section{¿Monismo Jurídico?: Casuismo, centralismo y magisterio de la Suprema Corte}

Ejemplos de todos los casos antes mencionados abundan en los expedientes de juicios de amparo, pero además se observa en ellos el centralismo ya denunciado por varios historiadores del derecho ${ }^{40}$. La República mexicana estaba organizada como federación y, por tanto, los estados tenían soberanía en cuanto a su administración interior en los ámbitos político-administrativo, judicial, educativo y fiscal. No obstante, al asumir la Suprema Corte demandas no sólo contra actos abusivos y/o inconstitucionales de las autoridades administrativas sino también contra las judiciales de los estados, revisaba $-\mathrm{y}$ no pocas veces enmendaba- las sentencias que emitían los juzgados locales y de

39 Ver Ejecutoria de la Suprema Corte de 11 de enero de 1882, correspondiente al juicio de amparo promovido por el representante de los vecinos del pueblo de Techuchulco (Estado de México), contra el acto judicial que dio posesión de unos terrenos al pueblo de Joquicingo, en Vallarta, 1896, tomo IV: 32-38.

${ }^{40}$ Fix-Zamudio y Cossío Díaz, 1996. Rhi Sausi (2010: 131-136) analiza las opiniones de la época porfirista, tanto los elogios a la homogeneización de criterios jurídicos por parte de connotados juristas (Vallarta, Rabasa), como las críticas de la prensa liberal por el avasallamiento del federalismo. 
distrito, anulando de esa manera la soberanía estatal en materia judicial, como se ha visto en varios de los amparos ya analizados. Ahora bien, esta actividad de los tribunales de distrito y la propia Suprema Corte permite analizar en los expedientes de amparo su función pedagógica, en cuanto a la cultura jurídica y constitucional vigente, puesto que instruía no sólo a actores corporativos en la cultura individualista liberal, sino además a las autoridades municipales, distritales y estatales, de los tres poderes, respecto de sus funciones y competencias, así como de los derechos y garantías de los ciudadanos que debían respetar. Al analizar este aspecto, se observa que ciertos conflictos por tierras tenían como detonante, en esta época, una iniciativa de un poder que excedía sus competencias e invadía la esfera del otro poder, de modo que el conflicto entre los actores locales escalaba hasta confrontar el más alto nivel de gobierno, o bien se originaba en el intento de autoridades administrativas por dirimir derechos de propiedad litigiosos, competencia que caía en la órbita del poder judicial. Detengámonos en algunos ejemplos sumamente ilustrativos al respecto.

En 1871, la junta municipal de San Bernabé Temoxtitla, distrito de Cholula, buscó ampararse contra el gobernador del estado de Puebla, porque erigió en pueblo a su ex barrio ${ }^{41}$ Santa Marta, trazando linderos que acortaban sus derechos de propiedad sobre terrenos comunales de pastos y leña. En este caso, el promotor fiscal pidió otorgar el amparo y presentó la argumentación más flexible sobre reconocer los derechos de propiedad colectivos y la presentación colectiva del amparo. También acusaba abuso de poder por parte del gobernador e invasión de las facultades del poder legislativo estatal, ya que erigir un nuevo municipio y modificar las jurisdicciones de los existentes era atribución de este poder, no del Ejecutivo. Por el contrario, el juez de distrito negó el amparo, presentando la argumentación individualista más restrictiva relativa a que los actores colectivos carecían de personalidad jurídica y de la capacidad para poseer terrenos comunales. Sin embargo, la Suprema Corte revocó la sentencia y, sin asumir los argumentos colectivistas del fiscal, otorgó el amparo para que pudiera dividirse el fundo legal entre los vecinos de San Bernabé. Pero no lo extendió a los efectos político-administrativos de la erección del pueblo de Santa Marta, dejando intacta la prerrogativa del gobierno estatal ${ }^{42}$. En apariencia el caso mostrado era un juicio menor por una cuestión tan tradicional como el pleito entre una cabecera y un sujeto de sólo cuarenta familias que se encontraba dentro del fundo legal de aquélla y que ya

${ }^{41}$ Barrio era la categoría decimonónica equivalente al «sujeto» colonial, esto es, una localidad dependiente de una cabecera municipal. Generalmente se utilizaba para aquellas localidades de amplia población indígena, organizada como comunidad.

${ }^{42}$ AHPJP, amparo 3/1871, $\mathrm{n}^{\circ}$ consecutivo 1547. 
en el siglo XVIII, durante el Primer Imperio y por tercera vez en 1869 había buscado separarse ${ }^{43}$. Sin embargo, una lectura cuidadosa del expediente arroja mayor información: el litigio más importante fue en realidad el que se entabló entre el Ejecutivo y el Legislativo estatales por dilucidar a quién correspondía establecer cuestiones tales como la división político-administrativa del estado.

En este tipo de juicios los más frecuentes eran litigios por tierras, dada la tradicional indefinición de linderos ${ }^{44}$. Resultaban casos complejos, puesto que involucraban una gran diversidad de actores -comunidades tradicionales, ayuntamientos, vecinos indígenas y no indígenas, haciendas o ranchos colindantes, otros pueblos del mismo o de otro municipio, e incluso de otro distrito; empresas del ferrocarril o de obras públicas; jefe político, juez de primera instancia, y hasta el gobernador y el congreso estatal- y, concurrentemente, distintos intereses y hasta culturas sobre el uso y tenencia de la tierra. Esto último no sólo se evidenciaba entre actores colectivos e individuales, o entre indígenas y no indígenas, sino incluso entre los mismos letrados (en este caso, entre el fiscal y el juez de distrito, pero, en ocasiones, aun entre los propios miembros de la Suprema Corte). La suma de todos estos factores determinaba una gran variación entre las sentencias de los amparos, incluso en casos que, en apariencia, pudieran ser similares, lo que limita deducir un razonamiento común para este tipo de casos. Pero ello no impide afirmar que ninguna autoridad civil o judicial quedó exenta de ser denunciada por arbitrariedad, incompetencia o abuso de poder, incluso por los vecinos más humildes de los pueblos. También, que los tribunales inferiores, y a veces los federales, solían denegar las presentaciones hechas por un colectivo indígena, presumiendo la actuación de la comunidad prohibida. No obstante, en esos casos, no siempre la Suprema Corte seguía el criterio del juez inferior y hubo casos en que lo enmendaba, aunque sólo a los efectos de determinar a quién

43 Ibidem: fs. 12-14. Esta larga duración de los litigios por tierras entre pueblos ya la habíamos destacado en el Amparo Gutiérrez, ver nota 30, ut supra.

${ }^{44}$ Ver, por ejemplo, Semanario Judicial de la Federación, $1^{\circ}$ época, tomo III: 493-495, amparo presentado en octubre de 1872 por vecinos de San Bernabé Tenoxtitla, distrito de Cholula, Puebla, contra su presidente municipal, quien por orden del jefe político los despojó de sus terrenos, no obstante haberlos desamortizado en 1861. El jefe político los entregó a vecinos de Ocoyucan para solucionar la disputa territorial entre ambos pueblos. El juez de distrito otorgó el amparo señalando que ésa no es facultad del jefe político, decisión ratificada por la Suprema Corte. Un caso muy similar, aunque entre dos particulares, se expresa en una sentencia que amparó, en mayo de 1873, a un ciudadano de Huehuetlán, Puebla, en la que el poder judicial consideró expropiatorio el proceder del jefe político, en Semanario Judicial de la Federación, $1^{\circ}$ época, tomo IV: 358-359. 
correspondía el derecho a la propiedad, pero obligando a desamortizar si esto no se había concretado aún.

Asimismo, más allá de las críticas que recibió el amparo como mecanismo de centralización política, se constata que la Suprema Corte era percibida como un árbitro más imparcial, mientras que las autoridades locales y estatales parecían actuar guiadas por filias e intereses, apoyando a una de las partes en juicio. Puede aseverarse, entonces, que en los litigios sobre terrenos resueltos por autoridades civiles, el amparo significó un límite consistente a los abusos de poder de éstas y su tendencia a inmiscuirse en asuntos de propiedad, que debían dirimirse por el poder judicial. Un ejemplo de ello lo representa el caso acaecido en febrero de 1873. Dos ciudadanos pidieron amparo contra actos del jefe político de Tepeji (Puebla), quien les había expropiado unos terrenos por orden de la Jefatura de Hacienda estatal, la que dio trámite a la solicitud de un particular que las había denunciado como tierras de cofradía. En el juicio, el fiscal recomendó amonestar al jefe político por haber obedecido a quien no tenía autoridad en la materia, puesto que si se afectaban derechos de particulares, debían dilucidarse en juicio. Es curioso que el fiscal le observa incluso al juez de distrito cuál era su función: «al Juzgado de su digno cargo toca enmendar el procedimiento, mandando que las cosas se restituyan al estado que guardaban antes de violarse la Constitución, que es el efecto de una sentencia que concede amparo». El juez de distrito otorgó el amparo, considerando que el jefe político «ha infringido el art. 16 por no ser competente para conocer en él [el negocio], así como el 27, por el ataque a la propiedad». La Suprema Corte lo confirmó ${ }^{45}$. Un amparo similar fue el otorgado a dos vecinos del pueblo de Coapam contra el jefe político de Tehuacán (Puebla), por despojarlos de los terrenos de su propiedad e impedirles hacer la siembra. El jefe político había seguido la opinión de la junta auxiliar de Coapam, que pidió las tierras de los individuos por considerar que las habían obtenido con fraude cuando uno de ellos integró la junta auxiliar. El juez de distrito otorgó el amparo, anulando la actuación del jefe político. Confirmó la Corte, «supuesta la oposición de los quejosos en cuestiones relativas a posesión y propiedad, el conocimiento y decisión de ellos no corresponde a la autoridad administrativa, sino a la judicial mediante el juicio respectivo: que por tanto es notoria en el presente caso la infracción del artículo $16 »^{46}$.

45 Semanario Judicial de la Federación, $1^{\circ}$ época, tomo III: 966-968.

${ }^{46}$ AHPJP, amparo 35/1887. La misma argumentación, en el amparo concedido el 31 de diciembre de 1872 a varios vecinos del pueblo de Nopalucan, distrito de Tepeaca (Puebla), contra actos del ayuntamiento que tomó parte de sus propiedades individuales (las habían titulado por trámite de desamortización en 1861). El juez de distrito argumentó infracción del art. 27 
Es interesante notar cómo, para poder hacer uso del amparo, los indígenas debían presentarse como propietarios de parcelas individuales, aludiendo a figuras como «varios vecinos», «un grupo de vecinos», «los vecinos individualmente considerados», cuando no como una «sociedad agrícola». Asimismo, para plantear abusos sobre la propiedad, si bien varios apelaron al artículo 16 constitucional, que establecía que nadie podía ser molestado en sus posesiones, sobre todo debían recurrir al artículo 27, el que precisamente establecía la propiedad individual como paradigma jurídico. En este sentido, en este artículo se sostiene la función didáctica del amparo, pues obligaba a los actores colectivos a asumir una identidad individual acorde al modelo constitucional liberal. Aún cuando sean muchos, como los cuatrocientos treinta y tres vecinos del Amparo Gutiérrez, o siquiera varios, como los treinta y siete de Tlamapa (municipio Santa Isabel Cholula, Puebla) que protestaban contra actos del jefe político de Atlixco. Este había ordenado arreglar las vías del tren, ocupando para ello terrenos particulares y destruyendo árboles y magueyes, con lo que consideraban violadas las garantías expuestas en el art. 27 constitucional: como propietarios afectados no se había solicitado su consentimiento ni procedido a la indemnización. Aunque fueron apoyados por el ayuntamiento de Cholula en su demanda, la junta auxiliar de Tlamapa respaldó al jefe político, así como otros vecinos de Tlamapa que trabajaban en las obras del ferrocarril. Peor aún, a diferencia de los dos casos anteriores, el juez de distrito negó el amparo por considerar que los daños no fueron irreparables ni se les había privado de la propiedad ${ }^{47}$.

\section{CONCLUSIONES}

Para concluir este trabajo se ofrecen algunas reflexiones generales resultantes del mismo. En primer lugar, se destaca la riqueza de los expedientes judiciales para complejizar una historia institucional lineal de la construcción de los estados nacionales, en general, y del derecho moderno, en particular. Así, se constata que los juicios de amparo que llegaron al circuito federal implicaban no sólo dilucidar cuestiones de límites y propiedad sobre la tierra,

\footnotetext{
constitucional, porque el presidente municipal debió haber formado expediente haciendo constar la causa de utilidad pública y la obtención del consentimiento de los propietarios afectados; tampoco demostró haber efectuado la indemnización correspondiente. La Suprema Corte ratificó la decisión del inferior, Semanario Judicial de la Federación, $1^{\circ}$ época, tomo III: 904-907.

${ }^{47}$ AHPJP, amparo 48/1882, $\mathrm{n}^{\circ}$ consecutivo 2544. El expediente no incluye la revisión de la Suprema Corte.
} 
sino además cuestiones jurisdiccionales. De un lado, se trataba de vigilar la acción legislativa de los estados (que no dictasen leyes contrarias a la constitución federal) y de vigilar la división de poderes; y, de otro, se pretendía apuntalar la autonomía del propio poder judicial, al sancionar y dar marcha atrás a la invasión de la órbita de competencia judicial por autoridades administrativas locales.

Las transacciones sociales y culturales entre todos los actores involucrados realizadas en la arena jurídica -y donde jugaban sus respectivas culturas jurídicas, sus intereses económicos, sus identidades sociales- permiten explicar la multiplicidad de los procesos estudiados, su larga trayectoria y sus dificultades de concreción. En este sentido, el peso de las formas comunales de propiedad de la tierra y la dificultad en individualizarla, influyeron en el criterio y la opinión de jueces, administradores y legisladores. Si los primeros tuvieron que aceptar la presencia de los actores tradicionales, pese a estar prohibida, los segundos idearon mecanismos, aún inconstitucionales, para cumplir con la ley de desamortización; siendo los terceros los responsables incluso de modificar la ley para permitir su participación jurídica, vía ineludible para deslindar los derechos sobre la propiedad.

Más específicamente, se ha podido corroborar en los casos analizados cómo operaba la transformación de las culturas jurídicas y, en particular, la función del amparo en educar a ciudadanos y autoridades de diversos niveles de las jerarquías judicial y administrativa sobre cuáles eran las garantías individuales y los procedimientos legales que debían respetarse en los procesos de disputa por terrenos y de expropiación por causa de utilidad pública, y qué autoridades eran competentes en cada caso. El aspecto didáctico de las ejecutorias de la Suprema Corte de Justicia se ha observado, primero, con respecto de los actores corporativos, al modelarlos como sujetos individuales por forzarles a demandar según el derecho nacional vigente; segundo, con respecto a los jueces locales y aún a los de distrito, al revisar sus sentencias y dictar la interpretación legal válida; y, tercero, con respecto de diversas autoridades de los niveles local, municipal, distrital y estatal que actuaban con criterios diferentes a los establecidos por las leyes: en ocasiones por corrupción o arbitrariedad, en otras por ignorancia. Y esto plantea una interesante cuestión de cultura jurídica: aun suponiendo que existía una efectiva coordinación entre los poderes y ámbitos del gobierno mexicano y que las ejecutorias de la Suprema Corte de Justicia sí lograran dar marcha atrás al acto reclamado, queda sin saberse, de todos modos, cuántas personas afectadas por casos similares no conocían y/o no denunciaban las fallas de procedimiento y la violación de sus derechos. 
En suma, este texto resalta la función pedagógica del amparo al erigir a la Suprema Corte como órgano decisivo en la construcción de la división de poderes, en la consolidación de la personalidad jurídica individual y aún en la conformación del sistema de propiedad privada. Lo hacía al resolver competencias y dudas legales; al confirmar o refutar sentencias -y sus argumentos- de los tribunales de distrito; al aceptar o desechar demandas de los pueblos respecto de los usos y la titularidad de los bienes inmuebles; y al anular actos de jefes políticos, ayuntamientos, jueces conciliadores, jueces de primera instancia y hasta de gobiernos y legislaturas estatales. En ese sentido, la enseñanza no era sólo para los ciudadanos, sino también para los funcionarios públicos y magistrados. Sin embargo, en la atribución de revisar las sentencias de los jueces inferiores, no pocos han visto un afán centralizador de la Suprema Corte, por tanto contradictorio del federalismo que proclamaba la constitución. Y esto mismo constituye una prueba notoria de que el monismo estatal, la personalidad individual y el respeto a las garantías individuales no eran aún hegemónicos en las prácticas jurídicas y políticas, si bien lo fuesen a nivel del discurso. En este sentido, se consideran muy atinadas las reflexiones de la nueva historia jurídica, y especialmente útiles para discutir la preeminencia, al menos historiográfica, del monismo jurídico decimonónico, que ha llevado a describir el periodo en términos de confrontación entre tradición y modernidad. En contrapartida, es plausible analizar el campo jurídico mexicano del último tercio del siglo XIX como un sistema en construcción y al juicio de amparo como un espacio para el aprendizaje de la nueva cultura jurídica.

\section{BIBLIOGRAFÍA}

Cabrera Acevedo, Lucio, La Suprema Corte a principios del porfirismo, 1877-1882, México, Poder Judicial de la Federación, 1990.

Colección de decretos del Congreso del Estado de México, 1824-1910, Toluca, Poder Legislativo, UAEM, El Colegio Mexiquense, 2001, 3 discos compactos.

Dublán, Manuel y Lozano, José María, Legislación mexicana o colección completa de las disposiciones expedidas desde la Independencia de la República, 52 vols., México, 1876-1912. Edición digital en DVD incluida en Mario Téllez y J. López Fontes (comps.), La Legislación Mexicana de Manuel Dublán y José María Lozano, México, Suprema Corte de Justicia de la Nación, Tribunal Superior de Justicia del Estado de México, El Colegio de México, Escuela Libre de Derecho, 2004. 
Escobar Ohmstede, Antonio, "La desamortización de tierras civiles corporativas en México: ¿una ley agraria, fiscal o ambas? Una aproximación a las tendencias en la historiografía”, Mundo Agrario, XIII/25 (La Plata, segundo semestre 2012): 1-33.

Fix-Zamudio, Héctor y Cossío Díaz, José R., El poder judicial en el ordenamiento mexicano, México, Fondo de Cultura Económica, 1996.

Garriga, Carlos, “Orden jurídico y poder político en el Antiguo Régimen”, Istor, IV/16 (México, primavera 2004): 13-44.

González Oropeza, Manuel (comp.), Ignacio Luis Vallarta. Archivo Inédito, tomo IV: Vallarta- Presidente de la Suprema Corte de Justicia de la Nación -1880-1882, México, Poder Judicial de la Federación, 1993.

Gutiérrez, José Blas, Nuevo Código de la Reforma. Colección de las disposiciones que se conocen con este nombre publicadas desde 1855 a 1870, 2 tomos, México, Imprenta de El Constitucional, 1869.

Hespanha, António Manuel, "Una nueva historia política e institucional”, Revista Mexicana de Ciencias Políticas y Sociales, XLI/166 (México, 1996): 9-45.

Lempérière, Annick, "De la república corporativa a la nación moderna: México (18211860)", Antonio Annino y François-Xavier Guerra (comps.), Inventando la nación: Iberoamérica, siglo XIX, México, Fondo de Cultura Económica, 2003: 316-346.

Lira, Andrés, El Amparo colonial y el Juicio de Amparo mexicano, México, Fondo de Cultura Económica, 1972.

Lira, Andrés, "El estado liberal y las corporaciones en México (1821-1859)", Antonio Annino, y François-Xavier Guerra, (comps.), Inventando la nación: Iberoamérica, siglo XIX, México, Fondo de Cultura Económica, 2003: 379-398.

Lira, Andrés y Staples, Ann, "Del desastre a la reconstrucción republicana, 18481876", Erick Velázquez García, et al., Nueva Historia General de México, México, El Colegio de México, 2010: 443-485.

Mallon, Florencia, Campesino y Nación. La construcción de México y Perú poscoloniales, México, El Colegio de San Luis, El Colegio de Michoacán, CIESAS, 2003.

Marino, Daniela, "La desamortización de las tierras de los pueblos (centro de México, siglo XIX). Balance historiográfico y fuentes para su estudio", América Latina en la Historia Económica. Boletín de Fuentes, 16 (México, 2001): 33-43.

Marino, Daniela, "Buscando su lugar en el mundo del derecho: actores colectivos y jurisprudencia en la Reforma", AAVV, Historia de la justicia en México, México, Suprema Corte de Justicia de la Nación, 2005a, vol. I: 235-262.

Marino, Daniela, "La modernidad a juicio. Pleitos por la tierra y la identidad comunal en el Estado de México, 1856-1910", Romana Falcón (comp.), Culturas de pobreza y resistencia. Estudios de marginados, proscritos y descontentos. México 1804-1940, México, El Colegio de México, Universidad Autónoma de Querétaro, 2005b: 237-264. 
Marino, Daniela, "El juzgado conciliador en la transición jurídica. Huixquilucan, Estado de México, 1856-1910”, Elisa Speckman y Claudia Agostoni (eds.), De normas y transgresiones. Enfermedad y crimen en América Latina, 1850-1950, México, Instituto de Investigaciones Históricas UNAM, 2005c: 195-224.

Marino, Daniela, "Indios, pueblos y la construcción de la Nación. La modernización del espacio rural en el centro de México", Erika Pani (coord.), Nación, Constitución y Reforma. 1821-1910, México, FCE, CIDE, 2010: 163-204.

Marino, Daniela y Zuleta, María Cecilia, “Una visión del campo. Tierra, propiedad y tendencias de la producción, 1850-1930”, Sandra Kuntz (coord.), Historia económica general de México, El Colegio de México, Secretaría de Economía, 2010: 437-472.

Morales Moreno, Humberto, Historia del Poder Judicial en el Estado de Puebla, 1826-2001. (El Tribunal Superior de Justicia y el Poder Judicial Federal), Puebla, Honorable Tribunal Superior de Justicia del Estado Libre y Soberano de Puebla, 2002.

Moreno Cora, Silvestre. Tratado del juicio de amparo conforme a las sentencias de los Tribunales, México, Tipografía y Litografía La Europea, 1902.

Rhi Sausi Garavito, María José, "Derecho y garantías: El juicio de amparo y la modernización jurídica liberal”, Erika Pani (coord.), Nación, Constitución y Reforma. 1821-1910, México, FCE, CIDE, 2010: 120-162.

Schaub, Jean-Frédéric, "L'histoire politique sans l'état: mutations et reformulations", Carlos Barros (ed.), Historia a Debate. Actas del Congreso Internacional "A História a Debate”, tomo III: Otros enfoques, Santiago de Compostela, Ed. Historia a Debate, 1995: 217-235.

Tena Ramírez, Felipe, Leyes Fundamentales de México, 1808-1957, México, Ed. Porrúa, 1957.

Vallarta, Ignacio L., Obras completas, tomo IV: Cuestiones constitucionales. Votos que como presidente de la Suprema Corte de Justicia dio en los negocios más notables resueltos por este Tribunal de $1^{\circ}$ de enero a 16 de noviembre de 1882 , México, Imprenta de J. J. Terrazas, 1896.

Vallejo, Jesús, "Paratonía de la historia jurídica", Mélanges de la Casa de Velázquez, XXXI/2 (Madrid, 1995): 109-141.

Fecha de recepción: 27 de febrero de 2015.

Fecha de aceptación: 6 de abril de 2015. 


\section{"The Extent of Their Existence". The Abolition of the Indian Communities and the Writ of Protection in the Disentailment Context. (Central Mexico, 1856-1910)}

This paper delves into the administrative and judicial process of the distribution of the communal property of the Indian population. It examines the consequences of some of the measures taken by the central Mexican states in order to overcome legal hurdles, as well as court decisions. By analyzing records of writs of protection presented by individuals, groups and villages, it aims to determine what the roles of the legislation, the jurisprudence and the judicial practices of the actors were in the transformation of the ownership culture, and how this process interwove with the constitution of State and citizenry.

Key words: writ of protection; Indian communities; disentailment; Central Mexico. 